\title{
Antifungal Effect of Magnesium Oxide,Zinc Oxide, Silicon Oxide and Copper Oxide Nanoparticles Against Candida albicans
}

\author{
Abbas Karimiyan, ${ }^{1}$ Hossein Najafzadeh, ${ }^{2, *}$ Masoud Ghorbanpour, ${ }^{3}$ and Seyed Hossein \\ Hekmati-Moghaddam ${ }^{4}$ \\ ${ }^{1}$ Department of Basic Sciences, Faculty of Veterinary Medicine, Shahid Chamran University, Ahvaz, IR Iran \\ ${ }^{2}$ Department of Pharmacology, Faculty of Veterinary Medicine, Shahid Chamran University, Ahvaz, IR Iran \\ ${ }^{3}$ Department of Microbiology, Faculty of Veterinary Medicine, Shahid Chamran University, Ahvaz, IR Iran \\ ${ }^{4}$ Department of Laboratory Medicine, Faculty of Paramedicine, Shahid Sadoughi University of Medical Sciences, Yazd, IR Iran \\ *Corresponding author: Hossein Najafzadeh, Department of Pharmacology, Faculty of Veterinary Medicine, Shahid Chamran University, Ahvaz, IR Iran. E-mail: najafzadeh@scu.ac.ir
}

Received 2013 March 1; Accepted 2013 June 12.

\begin{abstract}
Absrtact
Background: Candidiasis is the most common fungal infection in human and warm-blooded animals. Candida albicans, is an opportunistic pathogen in immune suppressed hosts, like HIV infected and under chemotherapy patients. Since, antifungal drugs are limited and challenged by resistance. Thus discovering agents with antifungal properties and minimum side effects and toxicity is essential. Nano-agents such as metal oxide nano-particles have unique properties such as high surface to volume ratio that introduce them as appropriate antimicrobial agents.

Materials and Methods: In this experimental study, antifungal effects of 4 nano-metal oxides; magnesium oxide, zinc oxide, silicon oxide and copper oxide ( $\mathrm{MgO}, \mathrm{SiO}_{2}, \mathrm{ZnO}$ and $\left.\mathrm{CuO}\right)$ were investigated in vitro against Candida albicans and compared with amphotericin B. Solution acetic acid was used for preparing nanoparticles suspensions. Minimum inhibitory concentration (MIC) and minimum fungicidal concentration (MFC) of these nano-particles were evaluated.

Results: The results showed that MIC of nano-MgO and nano $\mathrm{SiO}_{2}$ was greater than $3200 \mu \mathrm{g} / \mathrm{mL}$, but MIC and MFC of nano-ZnO was recorded $200 \mu \mathrm{g} / \mathrm{mL}$ and $400 \mu \mathrm{g} / \mathrm{mL}$, respectively. The MIC and MFC of nano-CuO was $400 \mu \mathrm{g} / \mathrm{mL}$. The MIC and MFC of amphotericin B was $0.5 \mu \mathrm{g} / \mathrm{mL}$ and $2 \mu \mathrm{g} / \mathrm{mL}$, respectively.

Conclusions: It is concluded that, $\mathrm{ZnO}$ and $\mathrm{CuO}$ nanoparticles have anti C. albicans properties and may be used in treatment of infections caused by this fungus that should be investigated in vivo.
\end{abstract}

Keywords: Nanoparticles, In Vitro, Candida albicans

\section{Background}

Developing resistance microbial strains against antibiotics is one of the important challenges in treatment of diseases. The limited choice of antifungal agents is also one of the most challengeable problems about fungal diseases $[1,2]$. Candida albicans is a polymorphus fungus that lives as natural floor of human and warm-blooded animals. But the conversions of host body in immunosuppressive diseases like HIV can let this yeast to cause different diseases. Some diseases from Candida (called candidiasis), are vulvovaginal candidiasis, oral lesions (thrush), mucocutaneus candidiasis in human and thrush and vaginal candidiasis in animals $[3,4]$.

Conventional drugs have several disadvantages including adverse effects, non-specificity of their action, and a lesser effectiveness due to ineffective in cancer chemotherapy and anti-diabetic therapy [5].

Among the new agents used as antimicrobials, nanoparticles are under especial attention. Nanoparticles have large surface to volume ratio that introduce them to better penetration in tissues and cells [6]. Some metal oxide nanoparticles including $\mathrm{ZnO}, \mathrm{CuO}$ and silver have anti-microbial effects [7, 8]. For example, Panacek el al. reported silver nanoparticle had better antifungal effect against candida by lesser concentration [9]. The antibacterial and antifungal activity of conventional (bulk) ZnO has been reported by Yamamoto [10] and Sawai and Yoshikawa [11]. Also it has been demonstrated ZnO nanoparticles possess significant antifungal properties against Botrytis cinerea and Penicillium expansum and the inhibitory effects increase by its concentrations [12]. ZnO nanoparticles increased intensity of lipid and protein bands in E. coli [7].

\section{Objectives}

Because the information about the anti-candidiasis effect of $\mathrm{SiO}_{2}, \mathrm{MgO}, \mathrm{CuO}$, and $\mathrm{ZnO}$ nanoparticles has not been assessed, this effect was investigated in vitro at present study.

Copyright ( ) 2015, Zahedan University of Medical Sciences. This is an open-access article distributed under the terms of the Creative Commons Attribution-NonCommercial 4.0 International License (http://creativecommons.org/licenses/by-nc/4.0/) which permits copy and redistribute the material just in noncommercial usages, provided the original work is properly cited. 


\section{Materials and Methods}

In this experimental study, the nanoparticles were provided from Iolitec Company, Germany. The particle size of $\mathrm{SiO}_{2}, \mathrm{MgO}, \mathrm{CuO}$ and $\mathrm{ZnO}$ respectively was $10,40,60$ and $20 \mathrm{~nm}$. The standard strain of the fungus, C. albicans, with reference number of PTTC10231 was obtained from the Iranian Center of industrial bacteria and fungi collections, Tehran.

\subsection{Preparing Culture Media}

Sabouraud dextrose agar medium was used for the first subcultures to harvest single colonies of the yeast. Sabouraud dextrose agar plates were used to determine MFC ranges. The RPMI 1640 culture medium was used for microdilution test.

\subsection{Fungal Suspension Preparation}

The standard strain of C. albicans was inoculated on Sabouraud dextrose agar medium and incubated for 48 hours in $37^{\circ} \mathrm{C}$, then, some colonies of the fungus were dissolved in distilled water, until the stiffness of suspension changed equal to $0.5 \mathrm{MC}$ farland. The 0.5 MC farland was prepared according to references $[1,13]$. The yeast concentration in this stiffness is about $1 \times 10^{6}-5 \times$ $10^{6} \mathrm{CFU} / \mathrm{mL}$.

\subsection{Minimum Inhibitory Concentration Determination}

MIC was determined visually after 48 hours incubation at $37^{\circ} \mathrm{C}$ and was defined as a concentration of drug which completely inhibited growth. Since the nanoparticles were insoluble in water, according to the producer factory guidelines, $5 \%$ acetic acid in distilled water was used for solvent. Sixteen milligram of each nanoparticle was solved in $1 \mathrm{~mL} 5 \%$ acetic acid and the resulted solutions were diluted 5 folds by the culture medium (RPMI 1640). After preparing the primary concentration, the final concentrations were selected 3200-1600-800-400200-100-50-25 $\mu \mathrm{g} / \mathrm{mL}$.
One hundred micro liter RPMI 1640 culture medium and 100 micro liter yeast suspension in 0.5 MC Farland dilution was added to these wells containing $100 \mu \mathrm{L}$ nanoparticles suspension. As control, only $200 \mu \mathrm{L}$ culture medium and $100 \mu \mathrm{L}$ yeast suspension were added to all the wells of one column. Also, in one column, serial dilutions of acetic acid were prepared as negative control (because the acid has inhibitory effect on yeast growth). In one column also, serial dilutions of amphotericin B (as positive control) $(64 \mu \mathrm{g} / \mathrm{mL}$ to $0.5 \mu \mathrm{g} / \mathrm{mL}$ ) was added to culture medium and yeast suspension. The trails were done in two separate microplates double repeatedly for each nanoparticle. The plates were incubated in $37^{\circ} \mathrm{C}$ for 48 hours.

\subsection{Minimum Fungicidal Concentration Determination}

The content of each clear well (no growth seen) was homogenized with a micropi-pette and the entire volume $(100 \mu \mathrm{L})$ of each of these wells was subcultured, onto two $90 \times 15 \mathrm{~mm}$ Sabouraud Dextroseagar (Difco) plates. To avoid anti-fungal carryover, aliquots were deposited as a spot onto the agar plate and allowed to soak. After the plate was dry, streaking was performed as described by Moore et al. to separate cells and remove them from the drug source [14]. All plates were incubated at $37^{\circ} \mathrm{C}$ for 48 hours. If C. albicans had growth on a plate, the equivalent concentration in microplates was recorded as MFC.

\section{Results}

MIC for nano $\mathrm{SiO}_{2}$ and nano $\mathrm{MgO}$ was greater than 3200 $\mu \mathrm{g} / \mathrm{mL}$. The MICs for nano $\mathrm{ZnO}$ and nano $\mathrm{CuO}$ were 200 $\mu \mathrm{g} / \mathrm{mL}$ and $400 \mu \mathrm{g} / \mathrm{mL}$, respectively. The MIC of amphotericin B was $0.5 \mu \mathrm{g} / \mathrm{mL}$.

The amounts of MFC for nano $\mathrm{ZnO}$ and nano $\mathrm{CuO}$ were both $400 \mu \mathrm{g} / \mathrm{mL}$. MFC for amphotericin B was $2 \mu \mathrm{g} / \mathrm{mL}$. The result of MICs and MFCs for the nanoparticles and amphotericin B was illustrated in Table 1. MFC for nano $\mathrm{SiO}_{2}$ and nano $\mathrm{MgO}$ was not observed.

Table 1. Mean of MIC and MFC of Nanoparticles and Amphotricin B Against Candida albicans

\begin{tabular}{lcc}
\hline Substance & Minimum Inhibitory Concentration (MIC) & Minimum Fungicidal Concentration (MFC) \\
\hline Amphotericin B, $\mu \mathrm{g} / \mathbf{m L}$ & 0.5 & 2 \\
\hline Nano ZnO, $\mu \mathrm{g} / \mathrm{mL}$ & 200 & 400 \\
Nano CuO, $\mu \mathrm{g} / \mathrm{mL}$ & 400 & 400 \\
Nano SiO $_{2}, \mu \mathrm{g} / \mathrm{mL}$ & $>3200$ & Not observed \\
\hline Nano MgO, $\mu \mathrm{g} / \mathrm{mL}$ & $>3200$ & Not observed \\
\hline
\end{tabular}




\section{Discussion}

Our study showed the amphotericin B had better antifungal effect than nanometals, but this property for nano-ZnO was greater than nano-CuO; while nano-MgO and nano $\mathrm{SiO}_{2}$ did not have antifungal effect against Candida albicans at in vitro condition.

According to our knowledge, this is the only study investigating the effect of these nanoparticles on $C$. albicans. Some studies investigated the effect of other nanoparticles on this yeast 1 . Different studies are available about the effect of nano $\mathrm{ZnO}$ on non C. albicans. The antifungal effects of nano $\mathrm{ZnO}$ were evaluated against pathogenic fungi (Penicillium expansum and Botrytis cinerea) [12, 15]. It was showed that nano-ZnO can considerably inhibit the growth of these two fungi in concentrations more than $3 \mathrm{mmol} / \mathrm{L}(138 \mu \mathrm{g} / \mathrm{mL})$ and completely stop their growth in concentrations more than $6 \mathrm{mmol} / \mathrm{L}(276 \mu \mathrm{g} / \mathrm{mL})[12,15]$. According to this study, nano-Zno has the potential of antifungal activity. Our study did not show any antifungal effects of $\mathrm{SiO}_{2}$ and MgO nanoparticles in concentrations $\leq 3200 \mu \mathrm{g} /$ $\mathrm{mL}$. The information about antifungal effects of these nanoparticles is limited. Some nanoparticles as silver induce apoptotic cell death in C. albicans by increasing of hydroxyl radicals [16]. However, shape of nanoparticle can influence its antimicrobial effects [17]. GarciaSaucedo et al. investigated the toxicity of $\mathrm{SiO}_{2}$ nanoparticles on yeast Saccharomyces cerevisiae, and showed that this nanoparticle is low effective or no effective on this yeast [18]. Similar studies on amphotericin B effect on $C$. albicans are available [19-21] and the results are close to the recent study.

Nanotechnology offers the possibility of designing new drugs with greater cell specificity and drug-release systems that act selectively on specific targets. This allows the administration of smaller but more effective doses, minimizing adverse effects. Nanotechnology can also be used to optimize drug formulations, increasing drug solubility and altering the pharmacokinetics to sustain the release of the drug, thereby prolonging its bioavailability [5].

Results of our study show by different size nanoparticles, although may be change their effects in similar size particles. Unfortunately we do not access to more data for comparison. It can be totally concluded that regardless to their mechanism of action, nano $\mathrm{ZnO}$ and nano $\mathrm{CuO}$, can be effective against $C$. albicans, and this subject can be examined more on different strains of this yeast and other fungi, and also can be investigated in vivo in next studies.

\section{Acknowledgments}

The authors wish to express their gratitude to the research council of Shahid Chamran University for their financial supports. This study was carried by 9058813 thesis number in faculty of veterinary medicine, Shahid Chamran University, Ahvaz, Iran.

\section{Footnotes}

Authors' Contribution:All authors had equal role in design, work, statistical analysis, and manuscript writing. Funding/Support:Shahid Chamran University of Ahvaz.

\section{References}

1. Kim KJ, Sung WS, Suh BK, Moon SK, Choi JS, Kim JG, et al. Antifungal activity and mode of action of silver nano-particles on Candida albicans. Biometals. 2009;22(2):235-42.

2. Goffeau A. Drug resistance: the fight against fungi. Nature. 2008;452(7187):541-2.

3. Fidel PJ. History and new insights into host defense against vaginal candidiasis. Trends Microbiol. 2004;12(5):220-7.

4. Lee HA, Hong S, Choe O, Kim O. Mural folliculitis and alopecia with cutaneous candidiasis in a beagle dog. Lab Anim Res. 2011;27(1):63-5.

5. Chekman IS. [Nanopharmacology: experimental and clinic aspect]. Lik Sprava. 2008;(3-4):104-9.

6. Niederberger M, Pinna N. Metal oxide nanoparticles in organic solvents.USA: Springer; 2009.

7. Liu Y, He L, Mustapha A, Li H, Hu ZQ, Lin M. Antibacterial activities of zinc oxide nanoparticles against Escherichia coli O157:H7. JAppl Microbiol. 2009;107(4):1193-201.

8. Raghupathi KR, Koodali RT, Manna AC. Size-dependent bacterial growth inhibition and mechanism of antibacterial activity of zinc oxide nanoparticles. Langmuir. 2011;27(7):4020-8.

9. Panacek A, Kolar M, Vecerova R, Prucek R, Soukupova J, Krystof V, et al. Antifungal activity of silver nanoparticles against Candida spp. Biomaterials. 2009;30(31):6333-40.

10. Yamamoto O. Influence of particle size on the antibacterial activity of zinc oxide. Int J Inorg Mater. 2001;3(7):643-6.

11. Sawai J, Yoshikawa T. Quantitative evaluation of antifungal activity of metallic oxide powders ( $\mathrm{MgO}, \mathrm{CaO}$ and $\mathrm{ZnO})$ by an indirect conductimetric assay. J Appl Microbiol. 2004;96(4):803-9.

12. He L, Liu Y, Mustapha A, Lin M. Antifungal activity of zinc oxide nanoparticles against Botrytis cinerea and Penicillium expansum. Microbiol Res. 2011;166(3):207-15.

13. Pfaller MA, Messer SA, Boyken L, Huynh H, Hollis RJ, Diekema DJ. In vitro activities of 5-fluorocytosine against 8,803 clinical isolates of Candida spp.: global assessment of primary resistance using National Committee for Clinical Laboratory Standards susceptibility testing methods. Antimicrob Agents Chemother. 2002;46(11):3518-21.

14. Moore $\mathrm{CB}$, Walls $\mathrm{CM}$, Denning DW. In vitro activities of terbinafine against Aspergillus species in comparison with those of itraconazole and amphotericin B. Antimicrob Agents Chemother. 2001;45(6):1882-5.

15. Jia H, Hou W, Wei L, Xu B, Liu X. The structures and antibacterial properties of nano-SiO2 supported silver/zinc-silver materials. Dent Mater. 2008;24(2):244-9.

16. Hwang IS, Lee J, Hwang JH, Kim KJ, Lee DG. Silver nanoparticles induce apoptotic cell death in Candida albicans through the increase of hydroxyl radicals. FEBS J. 2012;279(7):1327-38.

17. Khan MF, Hameedullah M, Ansari AH, Ahmad E, Lohani MB, Khan RH, et al. Flower-shaped ZnO nanoparticles synthesized by a novel approach at near-room temperatures with antibacterial and antifungal properties. Int J Nanomedicine. 2014;9:853-64.

18. Garcia-Saucedo C, Field JA, Otero-Gonzalez L, Sierra-Alvarez R. Low toxicity of $\mathrm{HfO} 2, \mathrm{SiO} 2, \mathrm{Al} 2 \mathrm{O} 3$ and $\mathrm{CeO} 2$ nanoparticles to the yeast, Saccharomyces cerevisiae. J Hazard Mater. 2011;192(3):1572-9.

19. Mahboubi M, Ghazian Bidgoli F. In vitro synergistic efficacy of combination of amphotericin B with Myrtus communis essential oil against clinical isolates of Candida albicans. Phytomedicine. 2010;17(10):771-4.

20. Karlowsky JA, Hoban DJ, Zhanel GG, Goldstein BP. In vitro interactions of anidulafungin with azole antifungals, amphotericin $\mathrm{B}$ and 5-fluorocytosine against Candida species. Int J Antimicrob Agents. 2006;27(2):174-7.

21. Canton E, Peman J, Gobernado M, Viudes A, Espinel-Ingroff A. Patterns of amphotericin B killing kinetics against seven Candida species. Antimicrob Agents Chemother. 2004;48(7):2477-82. 